Симоновский А.Я. Ставропольский государственный аграрный универстет, г. Ставрополь, Россия simonovchkij@mail.ru

\title{
ФАЗОВЫЕ ПРЕВРАЩЕНИЯ В СТАЛЯХ ПРИ УПРАВЛЯЕМОЙ ЗАКАЛКЕ В МАГНИТНОЙ ЖИДКОСТИ
}

Введение:

\begin{abstract}
в данной работе изучаются структуры и связанные с ними механические свойства ряда инструментальных сталей, подвергнутых закалочному охлаждению в магнитной жидкости с различным содержанием магнитной фазы при воздействии постоянного магнитного поля разной интенсивности. Возможность проведения в магнитной жидкости управляемой закалки определяется зависимостью интенсивности охлаждения от состава жидкости, величины и степени неоднородности магнитного поля, создаваемого вблизи охлаждаемой поверхности. Различная интенсивность охлаждения обусловливает различные механизмы фазовых превращений в стали в процессе закалки.
\end{abstract}

Материалы и методы:

Результаты исследования:

Обсуждение и заключения:

Ключевые слова: при выборе объекта исследования - образцов инструментальных сталей - исходили из закономерностей фазовых превращений, происходящих в сталях при различной интенсивности охлаждения. Поставленная цель достигалась выбором марок сталей характеризующихся различной степенью устойчивости переохлажденного аустенита и, тем самым, различной величиной критической скорости закалки - скорости охлаждения, обеспечивающей только бездифрфузионный механизм превращения аустенита.

впервые найдено, что путем изменения интенсивности магнитного поля при закалке в магнитной жидкости образцов малых размеров из сталей с пониженной устойчивостью переохлажденного аустенита можно управлять их твердостью.

результаты исследований позволили выявить новое перспективное направление при использовании магнитной жидкости в качестве закалочной среды - проведение закалочного охлаждения. магнитная жидкость, теплообмен, гидродинамика, магнитное поле, закалка стали. 
Simonovsky A.Ya. Stavropol State Agrarian University", Stavropol, Russia simonovchkij@mail.ru

\section{PHASE TRANSFORMATIONS IN STEELS UNDER CONTROLLED QUENCHING IN A MAGNETIC FLUID}

Introduction: In this paper we study structures and related mechanical properties of a number of tool steels subjected to quenching cooling in a magnetic fluid with different contents of the magnetic phase under the action of a constant magnetic field of different intensity. The possibility of controlled quenching in a magnetic fluid is determined by the dependence of the cooling intensity on the fluid composition, the magnitude and degree of inhomogeneity of the magnetic field created near the cooled surface. The different intensity of cooling causes different mechanisms of phase transformations in steel during the quenching process.

Materials and methods:

when choosing the object of research - samples of tool steels - proceeded from the regularities of phase transformations occurring in steels with different cooling intensities. The goal was achieved by the choice of steel grades characterized by varying degrees of stability of the supercooled austenite and, thus, a different value of the critical quenching rate, the cooling rate, which ensures only the diffusionless mechanism of austenite transformation.

Results of the study: for the first time it was found that by changing the intensity of the magnetic field during quenching in samples of small sizes of steels with lowered stability of supercooled austenite, their hardness can be controlled.

Discussion and conclusions:

the results of the research made it possible to identify a new promising direction when using a magnetic fluid as a quenching medium - performing hardening cooling.

Key words: $\quad$ magnetic fluid, heat transfer, hydrodynamics, magnetic field, quenching of steel.

\section{Введение}

В целом ряде работ [1..6] было показано, что магнитная жидкость может служить охлаждающей и закалочной средой в процессах интенсивного охлаждения нагретых до высоких температур твердых тел. Возможности управлять интенсивностью охлаждения при закалке обусловлены существенным влиянием магнитного поля на явления тепло-и массопереноса при кипении магнитной жидкости. Как будет показано в данной работе при определенных размерах закаливаемых образцов в магнитных полях в широком интервале их напряженности удается добиваться как бездиффузионного (мартенситного) так и диффузионного (перлитного) превращений при интен- 
сивном охлаждении стальных образцов в магнитных жидкостях, а так же промежуточного (бейнитного) превращения.

\section{Материалы и методы исследования}

При выборе объекта исследования - образцов инструментальных сталей - исходили из закономерностей фазовых превращений, происходящих в сталях при различной интенсивности охлаждения. Высокотемпературной фазой стали является аустенит [7]. При охлаждении стали до температур, ниже критических, аустенит претерпевает превращение. В зависимости от скорости охлаждения превращение аустенита с образованием окончательных структур может происходить при разных температурах. В peзультате медленного охлаждения превращение аустенита происходит при высоких температурах диффузионным путем, и окончательные структуры характеризуются высокой степенью равновесности. По мере увеличения скорости охлаждения диффузионные процессы в стали успевают происходить, однако, структура продуктов распада аустенита, оставаясь качественно подобной, характеризуется повышением степени дисперсности - сорбит и троостит. При закалочном охлаждении с высокими скоростями диффузионные процессы в стали произойти не успевают, поэтому перестройка гранецентрированной кубической решетки аустенита (Fe) в объемноцентрированную решетку феррита $(\mathrm{Fe})$ происходит сдвиговым путем с одновременной фиксацией углерода в решетке Fe. B результате образуется качественно новая фаза - пересыщенный твердый раствор - мартенсит. При выборе номенклатуры сталей для проведения экспериментов по закалке в магнитной жидкости основывались на стремлении обнаружить сталь, для которой интервал изменения скорости охлаждения в магнитной жидкости, обеспечиваемый наложением магнитного поля, охватывал бы область, характеризующуюся как перлитным - диффузионным, так и мартенситным - бездиффузионным превращением переохлажденного аустенита. Тем самым представлялось возможным наиболее полно оценить структурную чувствительность эффектов охлаждения в магнитной жидкости, достигаемых наложением магнитного поля.

Поставленная цель достигалась выбором марок сталей, характеризующихся различной степенью устойчивости переохлажденного аустенита и, тем самым, различной величиной критической скорости закалки - скорости охлаждения, обеспечивающей только бездиффузионный механизм превращения аустенита.

Применяли образцы из углеродистых сталей с различным содержанием углерода. Исследовались доэвтектоидная сталь 50 и эвтектоидная сталь У8. Образцы для анализа выполнялись цилиндрической формы диаметром 10 мм, высотой 35 мм. Выбор образцов достаточно малого диаметра был сделан по ряду причин. С одной стороны, руководствовались стремлением сопоставить результаты изучения интенсивности охлаждения в магнитной жидкости 
в условиях наложения магнитного поля, полученные в работах [1, 2, 3], с данными по изучению структуры и твердости образцов, закаленных в магнитной жидкости в полях различной интенсивности.

Для достижения критических скоростей закалки в слабоохлаждающей среде размер образцов должен быть мал. Наконец, при малых размерах образца можно ожидать, что обнаруженная ранее неоднородность охлаждения различных участков поверхности цилиндра [2..5] не приведет к сушественной неоднородности структуры и свойств образцов.

Образцы для закалки устанавливались на немагнитном направляющем штоке. Нагрев образцов с 10-минутной выдержкой для завершения превращений проводился в трубчатой электропечи. Температуры нагрева разных марок сталей под закалку выбирались в соответствии с рекомендациями $[8,9]$ и приведены в таблице 1. Там же указаны температуры критических точек этих сталей.

Охлаждение образцов осуществлялось быстрым вертикальным погружением в центр объема магнитной жидкости, заполнявшей немагнитный цилиндрический контейнер, расположенный в полюсах электромагнита.

В качестве показателя механических свойств закаленных образцов определялась их твердость. Измерение твердости проводилось на приборе Роквелла по шкале С в трех сечениях: центральном и двух крайних, расположенных на расстоянии 3-5 мм от торцов. Значение твердости и характеристики рассеяния результатов измерений принимались по всем замерам для серии образцов, обработанных при одном режиме. Доверительный интервал определялся при доверительной вероятности 0,95 .

Характер полученных структур изучали путем приготовления микрошлифов по методике, описанной в [10], и исследования их в светлом поле горизонтального металлографического микроскопа МИМ-8М при увеличении $900 \mathrm{X}$.

Рентгеноструктурный анализ проводился на рентгеноструктурном дифрактометре ДРОН-2,0 в излучении железного анода. Длина волны излучения $1,936 \AA$ при рабочем напряжении 25 кВ и токе 24 мА. Диаметр диафрагмы на трубке составлял 2 мм. Применяемый фильтр - стандартный марганце-

Таблица 1. ТЕМПЕРАТУРЫ НАГРЕВА ПОД ЗАКАПКУ И КРИТИЧЕСКИЕ ТОЧКИ ИСПОЛЬЗУЕМЫХ МАРОК СТАЛЕЙ

Table 1. Temperatures for quenching and critical points used steel grades

\begin{tabular}{l|l|l|l}
\hline Марка стали & $\begin{array}{l}\text { Температура } \\
\text { нагрева под закалку }\end{array}$ & \multicolumn{2}{|l}{ Температура критических точек сталей $[8,9],{ }^{\circ} \mathrm{C}$} \\
\cline { 2 - 4 } & 880 & 725 & Aс3 \\
\hline Сталь 50 & 820 & 720 & 740 \\
\hline У8 & & & \\
\hline
\end{tabular}


вый. Регистрация излучения проводилась сцинтилляционным счетчиком. Измерительная щель на счетчике составляла 1 мм. Запись показаний счетчика осуществлялась потенциометром КСП-4. Обработка рентгенограмм проводилась по методике, изложенной в [10].

\section{Результаты исследования и их обсуждения}

Твердость и структура доэвтектоидной стали после закалки в магнитной жидкости. В результате предварительных экспериментов было показано, что наилучшие результаты получаются при закалке образцов в растворах магнитной жидкости с объемной долей магнитной фазы в пределах $0,0023 \leq \varphi_{m} \leq 0,0374$. Это связано с благоприятным сочетанием для указанных растворов магнитных и теплофизических свойств, определяющих длительность и интенсивность пленочного и пузырькового режимов охлаждения. Для растворов с объемной долей магнитной фазы $\varphi_{m}>0,0374$ охлаждение в режиме пленочного кипения распространяется до температур начала мартенситного превращения. Температура начала мартенситного превращения для выбранных марок сталей лежит в пределах 3000 С. На поверхности образцов визуально наблюдается значительный рост налета расслоившихся частиц магнитной фазы. За счет этого охлаждающая способность концентрированных растворов жидкости резко снижается. Растворы магнитной жидкости с объемной долей магнитной фазы $\varphi_{m}<0,0023$ в значительной степени утрачивают магнитные свойства, что ослабляет влияние магнитного поля на процессы охлаждения. В то же время, в составе раствора, несмотря на значительное разбавление несущей жидкостью, остается достаточно большое количество поверхностно-активных веществ, присутствие которых и обусловливает низкую охлаждающую способность магнитной жидкости в сравнении с охлаждающей способностью несущей среды.

Низкая охлаждающая способность и слабое влияние магнитного поля на интенсивность охлаждения в растворах с $\varphi_{m}<0,0023$ и $\varphi_{m}>0,0374$ не позволяют эффективно проводить в них закалку и добиваться высокой твердости у закаленных образцов.

На рис. 1 приведены результаты измерения твердости образцов стали 50 , закаленных в растворах магнитной жидкости с объемной долей магнитной фазы в полях различной интенсивности.

Видно, что наложение магнитного поля приводит к существенному увеличению твердости образцов. При закалке в растворах с объемной долей магнитной фазы $\varphi_{m}=0,0294$ заметные изменения происходят уже в сравнительно малом по величине магнитном поле. Изменения носят скачкообразный характер. Однако, в связи с непрерывным изменением скорости охлаждения в магнитной жидкости, с ростом величины магнитного поля точки на графиках соединены непрерывными линиями. Следует отметить, что скачкообразный характер изменения твердости образцов при непрерывном 


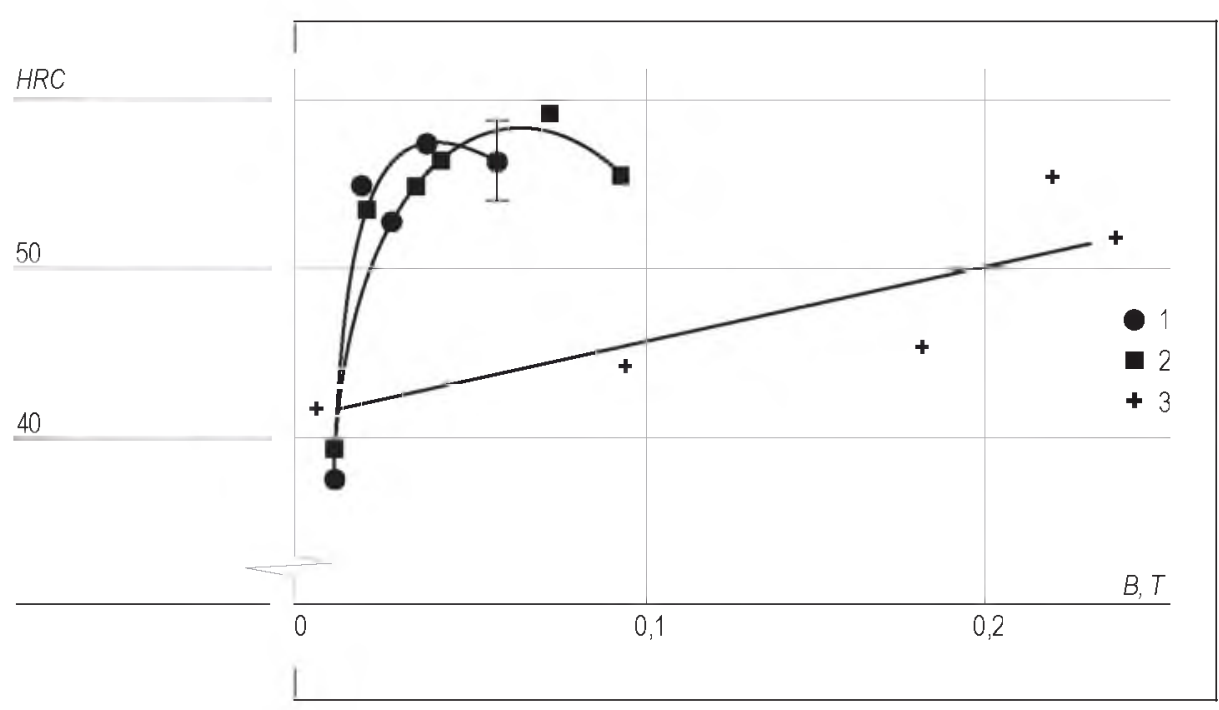

Рис. 1. График зависимости твердости образцов из стали 50 от величины прикладываемого магнитного поля при закалке в магнитной жидкости с объемной долей магнитной фазы, $\varphi_{m}: 1-0,0294 ; 2-0,0159 ; 3-0,0023$.

Fig. 1. Graph of the hardness of samples from steel 50 as a function of the applied magnetic field when quenched in a magnetic fluid with a volume fraction of the magnetic phase $\varphi_{m}: 1-0.0229 ; 2-$ $0.0159 ; 3-0.0023$.

изменении скорости охлаждения связан с отсутствием в применяемых сталях (сталь 50 и У8) промежуточного - бейнитного - превращения [7]. Существенные изменения твердости образцов при закалке в растворах магнитной жидкости с $\varphi_{m}=0,0023$ происходят в значительном по величине магнитном поле. Максимум на кривых зависимости твердости образцов от величины прикладываемого магнитного поля обусловлен наличием максимума зависимости интенсивности охлаждения в магнитной жидкости в интервале температур мартенситного превращения ( 3000 C) от величины приложенного магнитного поля.

На рис. 2 приведены фотографии микроструктур образцов из стали 50 , подвергнутых закалке в магнитной жидкости с объемной долей магнитной фазы $\varphi_{m}=0,0294$. Структура образцов, подвергнутых закалке в отсутствие магнитного поля (рис. 2а), состоит из примерно равной доли продуктов диффузионного и бездиффузионного преврашения. На фотографии светлые области - мартенсит. Отчетливо видны характерные мартенситные иглы. Темные области - троостит. Анализ структуры подтверждается измерениями твердости образцов. Твердость $40 \mathrm{HRC}$ соответствует полумартенситной зоне стандартной торцовой пробы для стали с содержанием углерода $0,5 \%$ [11]. На 
рис. $2 б$ приведена фотография микроструктуры стали 50 , полученной при закалке в малом по величине магнитном поле. На фотографии темные области с большеугловыми границами - троостит. Области игольчатой формы на светлом фоне - мартенсит. Видно, что уже в малом магнитном поле для образцов применяемого размера скорость охлаждения близка к критической - превалирует бездиффузионное превращение переохлажденного аустенита. Дальнейшее увеличение магнитного поля уже не приводит к существенным изменениям в структуре образцов. На рис. 2 в приведена фотография микроструктуры стали 50, полученной при закалке в поле 0,0220 Т. Отчетливо видны характерные морфологические признаки мартенсита - игольчатая форма темных включений. Однако здесь еще могут наблюдаться отдельные области трооститных включений.

a
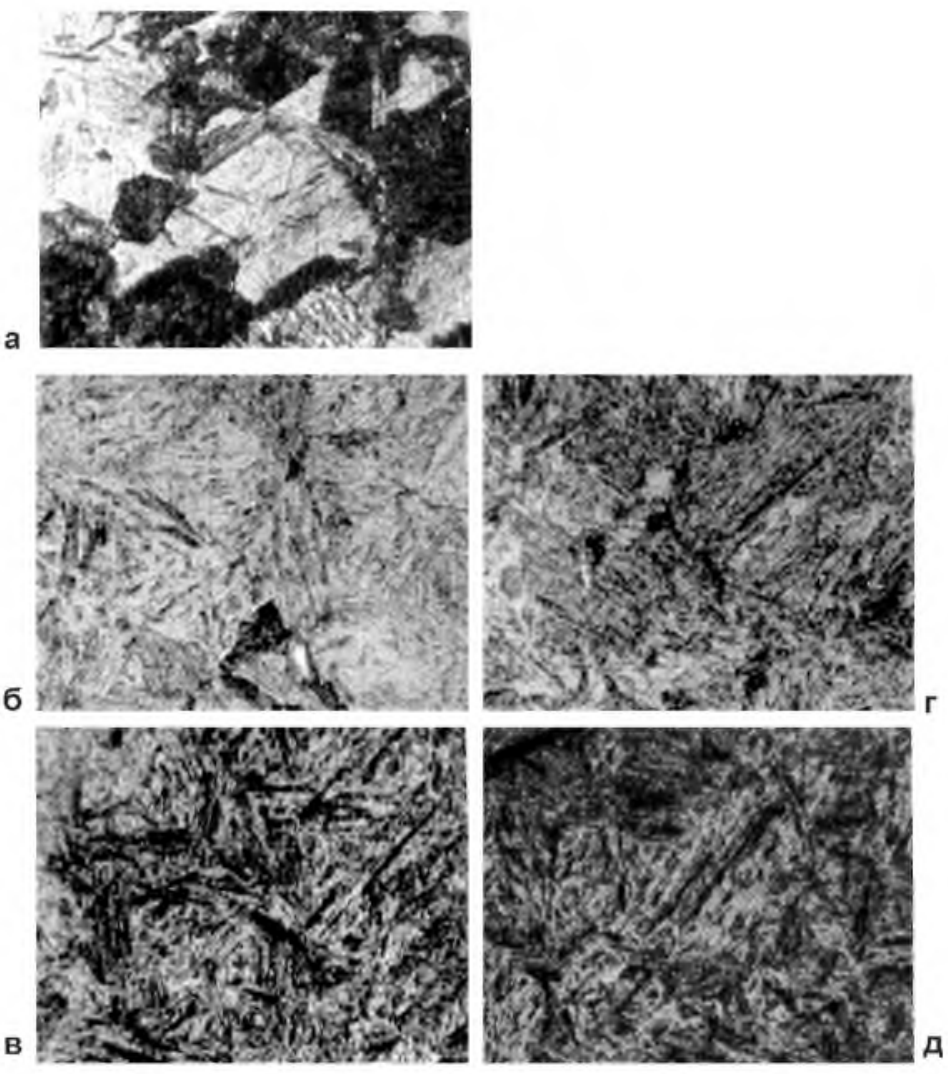

Рис. 2.

Микроструктуры стали 50 после закалки в магнитной жидкости $\left(\varphi_{m}=0,0294\right)$ в магнитных полях, Т: $а$ - 0; $6-0,0140$; в - 0,0220; г - 0,0370; д - 0,0525.

Fig. 2. Microstructures of steel 50 after quenching in a magnetic fluid $\left(\varphi_{m}=0.0294\right)$ in magnetic fields, $\mathrm{T}: \mathrm{a}-0 ; \mathrm{b}-0.0140$; B 0,$0220 ; g-0.0370 ; d-0.0525$. 

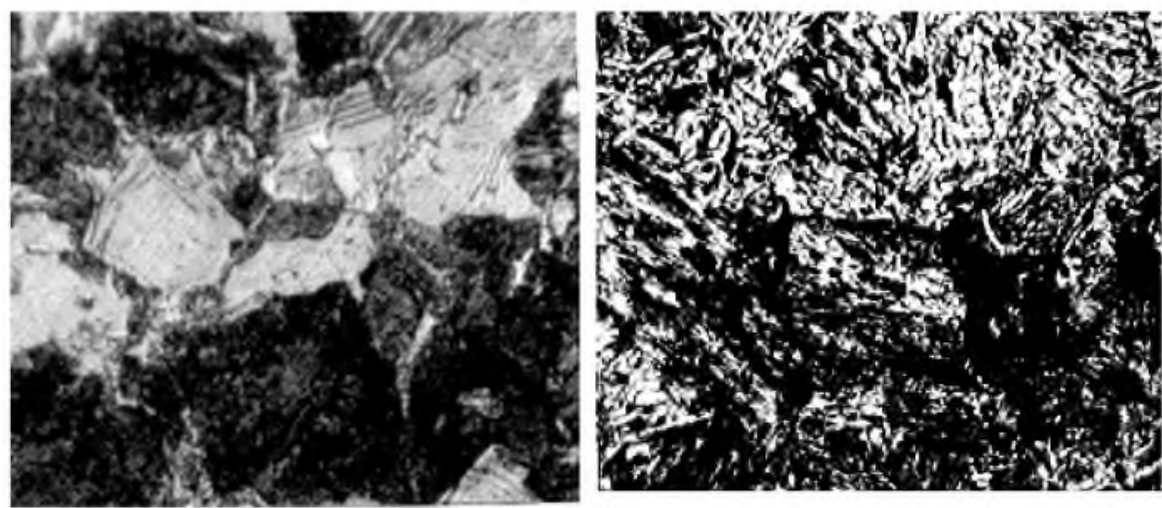

a

б

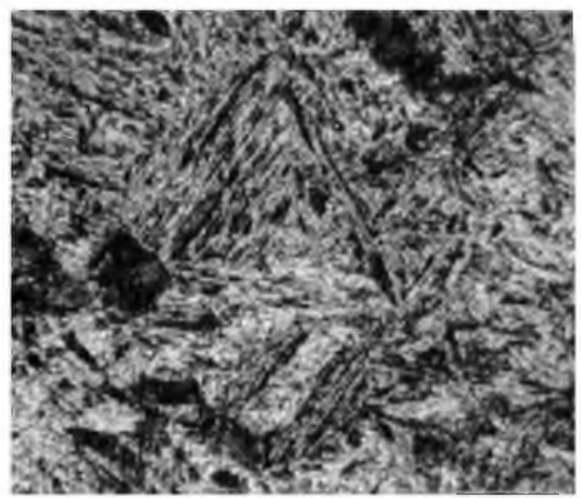

B

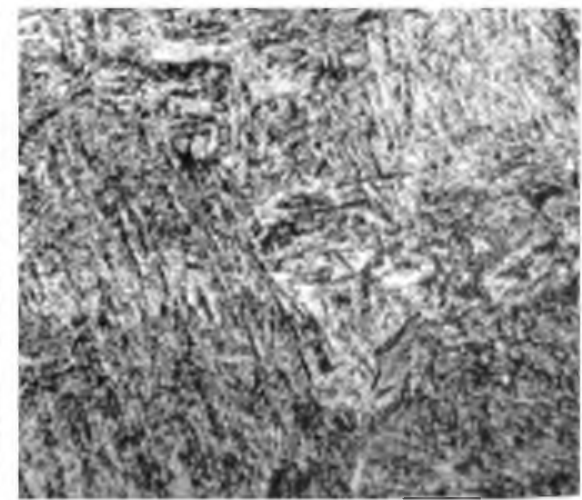

r
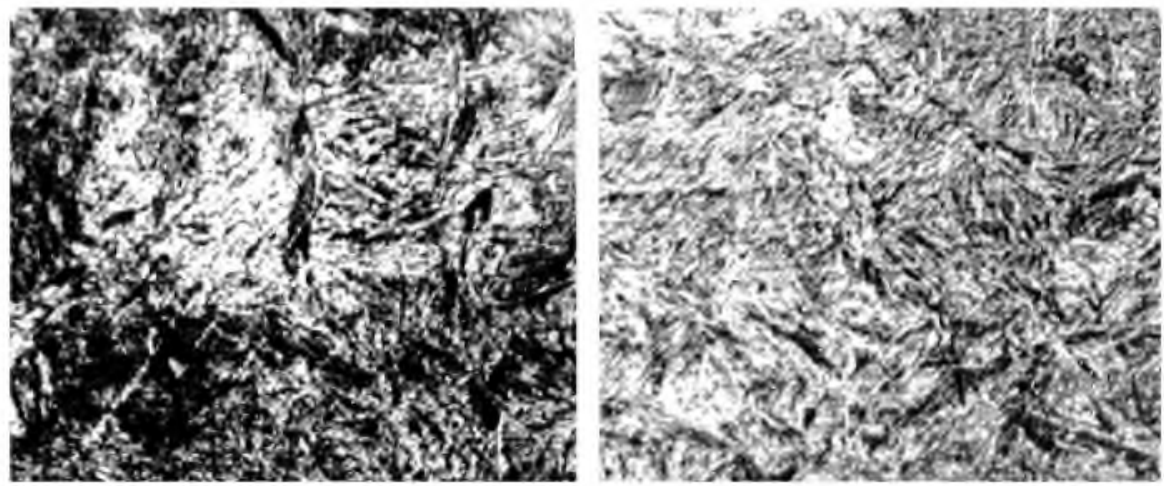

म

Рис. 3.

Микроструктуры стали 50 после закалки в магнитной жидкости $\left(\varphi_{m}=0,0159\right)$ в магнитных полях, Т: a - 0; $6-0,0220$; в - 0,0370; г - 0,0525; д-0,0680; e-0,0980.

Fig. 3. Microstructures of steel 50 after quenching in a magnetic fluid $\left(\varphi_{m}=0.0159\right)$ in magnetic fields, $\mathrm{T}$ : $\mathrm{a}-0 ; \mathrm{b}-0.0220 ; \mathrm{B}-0,0370$ $\mathrm{g}-0.0525 ;$ д $-0,0680 ; \mathrm{e}-0.0980$. 
На рис. 2 г и д приведены фотографии микроструктур образцов из стали 50, закаленных в магнитных полях $0,0370 \mathrm{~T}$ и $0,0525 \mathrm{~T}$ соответственно. Структура образцов в обоих случаях - мартенсит. На фотографиях видна игольчатая форма темных включений. Однако по мере увеличения магнитного поля наблюдается тенденция к укрупнению темных включений - характерный признак процессов отпуска. По-видимому, это следствие максимума во влиянии магнитного поля на интенсивность процесса охлаждения в магнитной жидкости в интервале температур мартенситного превращения. Снижение скорости охлаждения в интервале температур мартенситного превращения с ростом величины прикладываемого магнитного поля приводит к возможности протекания процессов низкотемпературного отпуска.

При закалочном охлаждении образцов из стали 50 в магнитной жидкости с объемной долей магнитной фазы $\varphi_{m}=0,0159$ характер фазовых превращений аналогичен происходящим при закалке в жидкости с $\varphi_{m}=0,0294$.

На рис. 3 а приведена фотография микроструктуры стали 50 после закалки в магнитной жидкости с $\varphi_{m}=0,0159$ без магнитного поля. Сравнительный анализ твердости и морфологических особенностей структуры стали показывает, что здесь присутствуют продукты диффузионного и бездиффузионного превращения. При твердости $40 \mathrm{HRC}$ для стали с содержанием углерода $\sim 0,5 \%$ в объеме образца присутствует $\sim 50 \%$ троостита и $\sim 50 \%$ мартенсита. На фотографии светлые области, в объеме которых видны иглообразные включения - мартенсит, темные области - троостит.

При закалке образцов в магнитном поле в жидкости с объемной долей магнитной фазы $\varphi_{m}=0,0159$ удается плавно управлять составом фаз в сталях. На рис. $3 б$ и Зв приведены фотографии микроструктур стали 50 после закалки в магнитных полях $0,0220 \mathrm{~T}$ и $0,0370 \mathrm{~T}$ соответственно. На фотографии темные игловидные образования на светлом фоне - мартенсит.

Темные вкрапления с большеугловыми границами - троостит. В таком же по величине магнитном поле $(0,0370 \mathrm{~T})$ при закалке в жидкости $\varphi_{m}=0,0294$ трооститные включения практически отсутствовали. Дальнейшее увеличение магнитного поля при закалке в жидкости с объемной долей магнитной фазы $\varphi_{m}=0,0159$ приводит к исчезновению в структуре продуктов диффузионного превращения. В подтверждение этого на рис. 3г приведена фотография микроструктуры стали 50, полученная при закалке в магнитном поле 0,0525 Т. Видно, что структура стали - мартенсит. При закалке в магнитной жидкости с $\varphi_{m}=0,0159$ в магнитном поле, большем 0,0525 Т, в структуре могут обнаруживаться последствия процессов отпуска. На рис. 3 д и е приведены фотографии микроструктур стали 50, полученных при закалке в магнитных полях 0,0680 и 0,980 Т соответственно. Видно, что игольчатые образования укрупнены. С уменьшением объемной доли магнитной фазы в магнитной жидкости удается все более плавно управлять составом фаз в стали в результате закалки. 


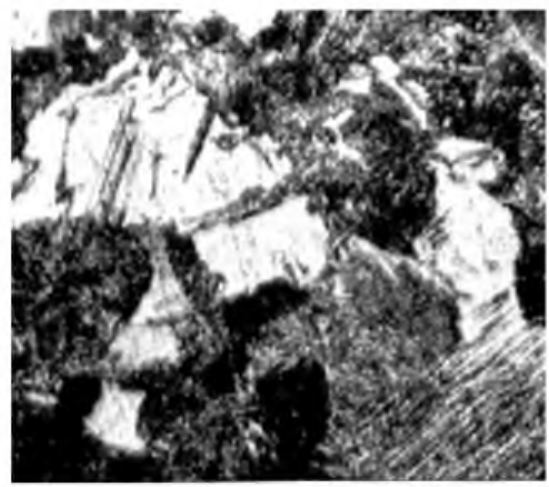

a

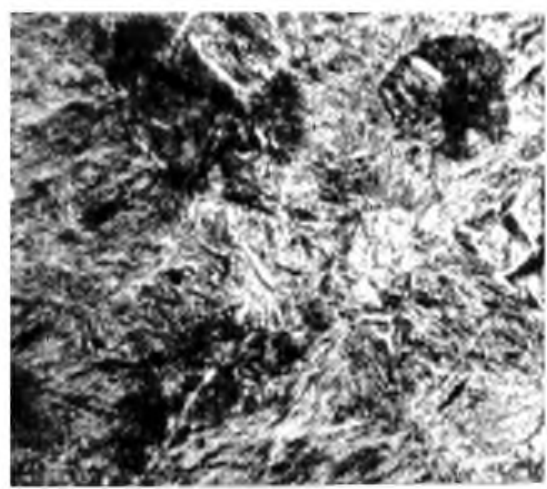

B

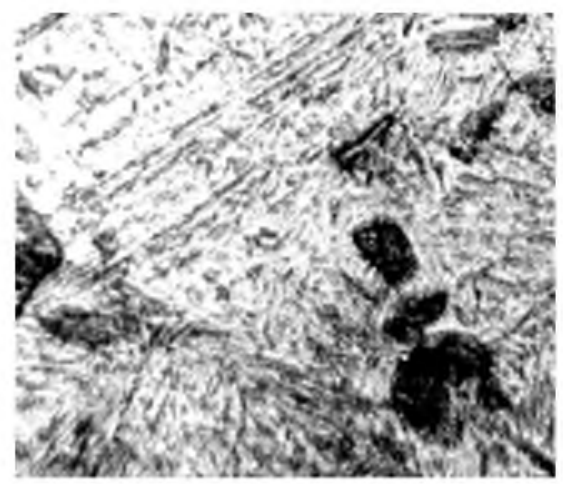

д

Рис. 4

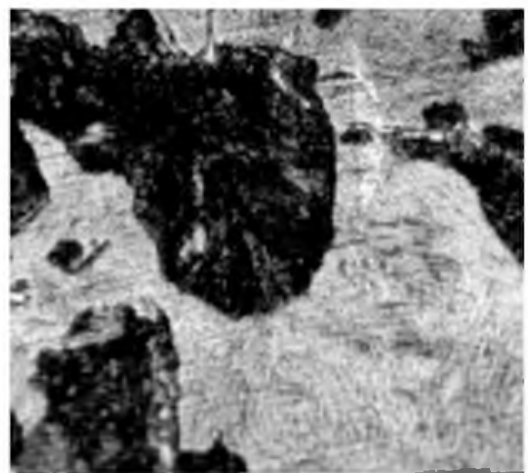

6

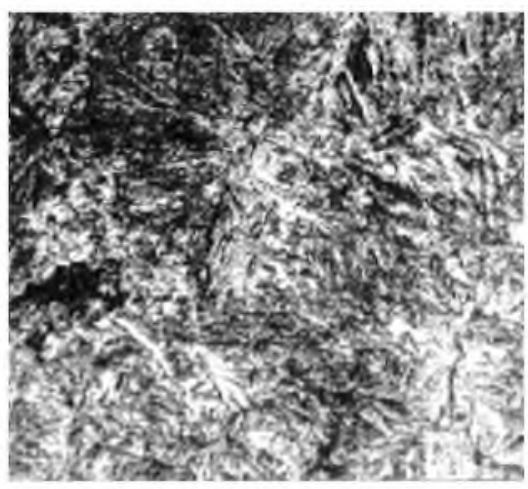


Однако величина прикладываемого магнитного поля, необходимого для управления процессом, существенно возрастает.

На рис. 4 а приведена фотография микроструктуры стали 50, закаленной в магнитной жидкости с объемной долей магнитной фазы $\varphi_{m}=0,0023$ в отсутствие магнитного поля. Как и при закалке в жидкостях с $\varphi_{m}=0,0294$ и $\varphi_{m}=0,0159$ в отсутствие магнитного поля, твердость образцов соответствует полумартенситной зоне (40 HRC). в структуре присутствует $\sim 50 \%$ мартенсита и $\sim 50 \%$ троостита. На фотографии эти области видны соответственно как светлая с наличием игольчатых образований и темная с участками большей и меньшей протравленности - участки более и менее темные. Последнее связано с наличием в структуре мелкодисперсной и грубодисперсной фаз.

Наложение магнитного поля приводит к последовательному уменьшению объема трооститных включений в структуре стали.

На рис. 4 б - 4 д приведены фотографии микроструктур стали 50, закаленной в магнитной жидкости с $\varphi_{m}=0,0023$ в магнитном поле. Из фотографий видно, что с увеличением магнитного поля объем темных пятен с большеугловыми границами хорошо протравленной мелкодисперсной фазы - троостита - уменьшается.

\section{Закалка эвтектоидной и низколегированной сталей в магнитных жидкостях}

С увеличением содержания углерода в стали снижается критическая скорость закалки, однако, увеличивается предельная твердость закаленных образцов. Несмотря на меньшую критическую скорость закалки стали У8 в сравнении со сталью 50, твердость образцов из стали У8, закаленных в магнитной жидкости в отсутствие поля, оказалась ниже твердости образцов из стали 50, обработанных в аналогичных условиях. На рис. 5 приведены результаты измерения твердости образцов из стали У8, подвергнутых закалке в растворах магнитной жидкости с объемной долей магнитной фазы в пределах $0,0023 \leq \varphi_{m} \leq 0,0374$ в магнитном поле различной интенсивности.

При закалке в наиболее концентрированном растворе в отсутствие поля твердость образцов не превысила $30 \mathrm{HRC}$. Напомним, что в аналогичных условиях твердость образцов стали 50 составила $40 \mathrm{HRC}$. Подобный эффект объясняется различием температуры нагрева под закалку этих марок сталей.

С ростом температуры нагрева увеличивается начальная разность температуры образца и охлаждающей жидкости. Это приводит к более интенсивному охлаждению образца в высокотемпературной области [7]. В связи с более низкой температурой нагрева под закалку стали У8, охлаждение образцов в области температур перлитного превращения происходило медленнее, что способствовало диффузионным процессам в стали. 


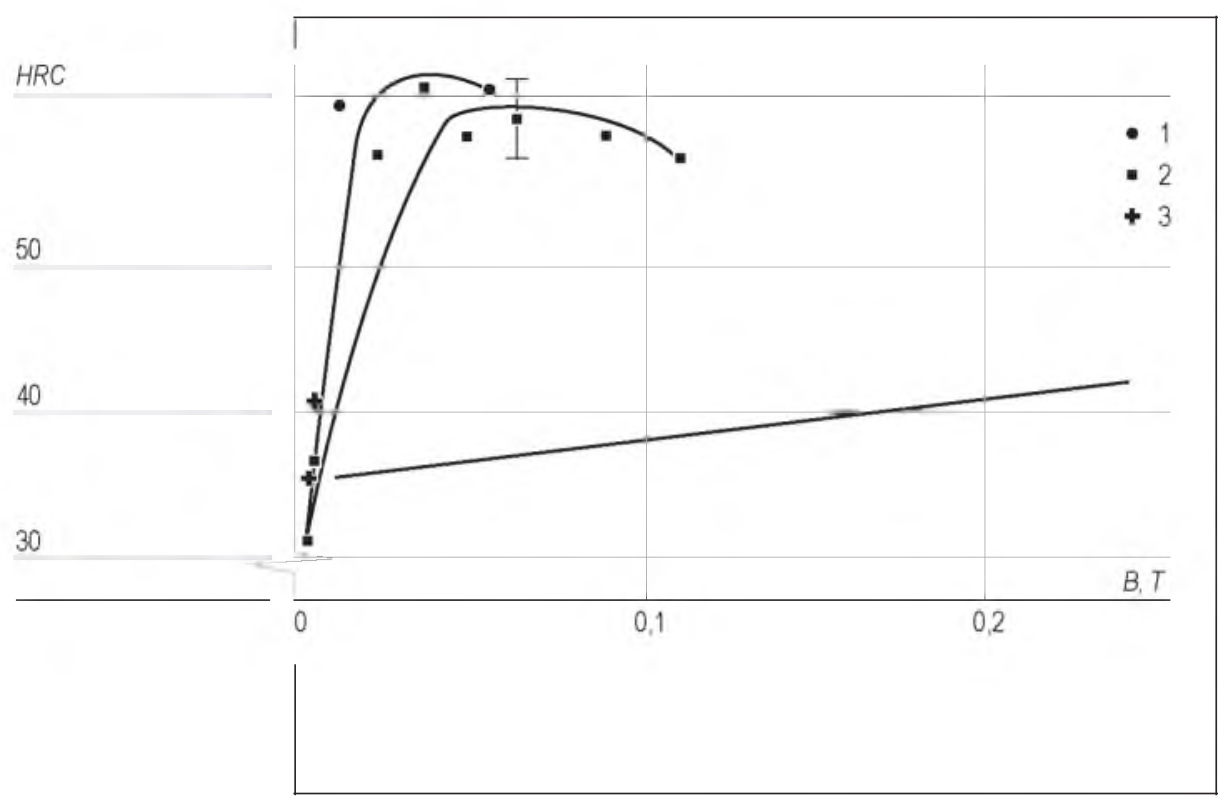

Pnc. 5.

График зависимости твердости образцов из стали У8 от величины прикладываемого магнитного поля при закалке в магнитной жидкости с объемной долей магнитной фазы, $\varphi_{m}: 1-0,0294 ; 2-0,0159 ; 3-0,0023$.

Fig. 5. The graph of the dependence of the hardness of the samples from $Y 8$ steel on the magnitude of the applied magnetic field upon quenching in a magnetic fluid with a volume fraction of the magnetic phase: $1-0.0229 ; 2-0.0159 ; 3-0.0023$.

На рис. 6 а приведена фотография микроструктуры стали У8, полученной в результате закалки в магнитной жидкости с объемной долей магнитной фазы $\varphi_{m}=0,0294$ в отсутствие магнитного поля. На фотографии хорошо видны светлые области, где практически сформировалась равновесная структура - перлит. На фотографии на светлом фоне феррита видны тонкие пластины цементита. Однако, в большом объеме в структуре обнаруживаются мелкодисперсные перлитоподобные фазы - сорбит и троостит. На фотографии они выглядят как менее темные (слабо протравленные) и более темные (сильно протравленные) области. При закалке в концентрированном растворе магнитной жидкости $\left(\varphi_{m}=0,0294\right)$ уже в малом по величине маг- 


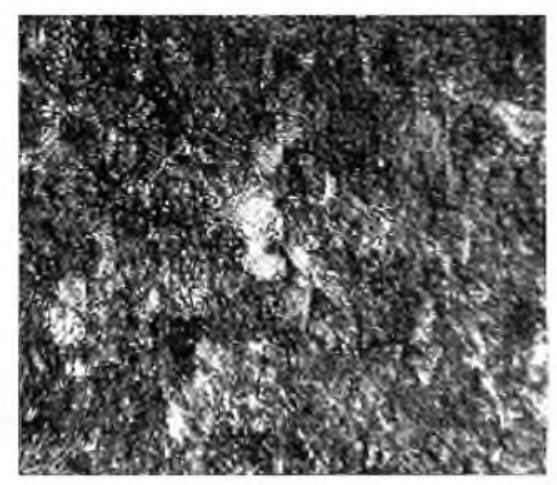

a

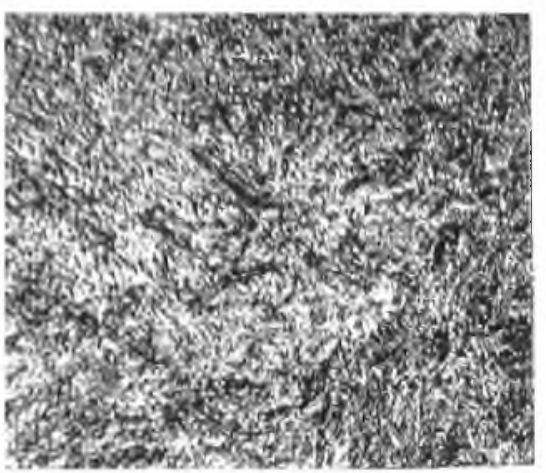

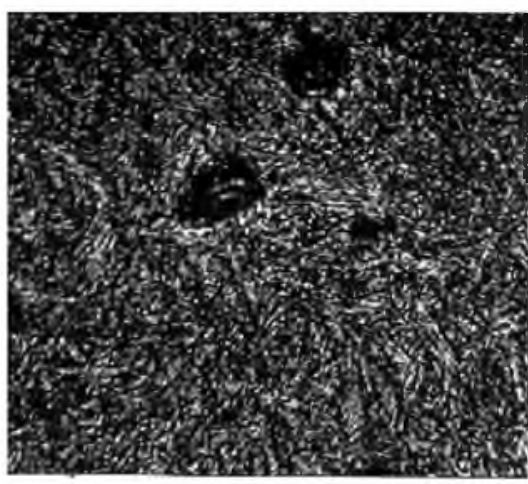

б

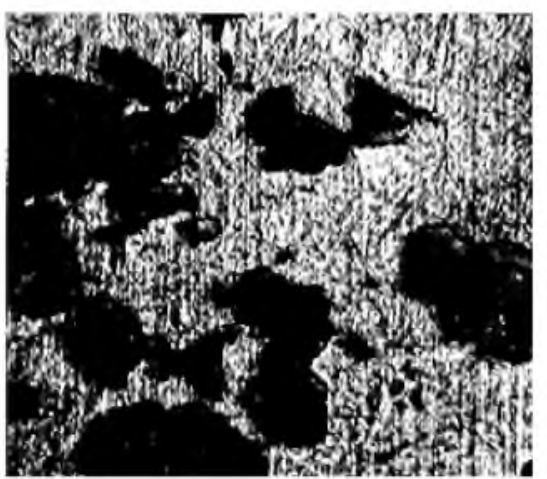

Pис. 6.

Микроструктуры стали У8 после закалки в магнитной жидкости $\left(\varphi_{m}=0,0294\right)$ в магнитных полях, $\mathrm{T}: \mathbf{a}-0 ; \mathbf{\sigma}-0,0220 ; \mathbf{B}-0,0370 ; \mathbf{r}-0,0525$.

Fig. 6 . The microstructures of steel $U 8$ after quenching in a magnetic liquid $\left(\varphi_{m}=0.0294\right)$ in magnetic fields,

$\mathrm{T}: \mathrm{a}=0 ; \mathrm{b}-0.0220 ; \mathrm{B}-0,0370 ; \mathrm{g}-0.0525$

нитном поле бездиффузионное превращение преобладает. На рис. 6 б, где приведена фотография микроструктуры стали У8 после закалки в магнитном поле $0,0220 \mathrm{~T}$, видны редко расположенные темные пятна троостита. Основная структура стали - мелкоигольчатый мартенсит. При закалке в магнитном поле $0,0370 \mathrm{~T}$, как следует из фотографии рис. 6 в, троостиные включения в структуре уже не обнаруживаются. При закалке стали У8 максимум влияния поля более выражен. На рис. 6 г приведена фотография микроструктуры стали У8, полученной в результате закалки в магнитном поле 0,0525 Т. Видно, что трооститные включения - на фотографии это темные пятна с большеугловыми границами - вновь появляются и занимают значительный относительный объем в структуре. 


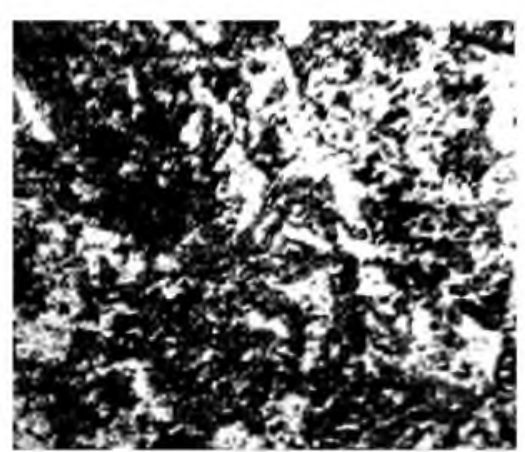

a

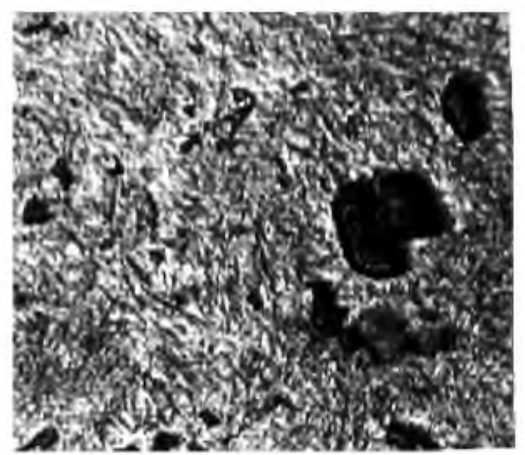

B
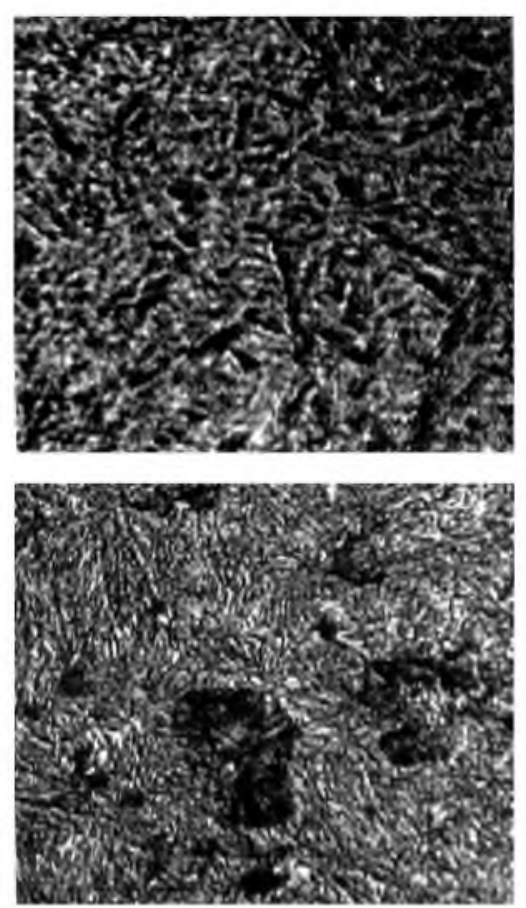

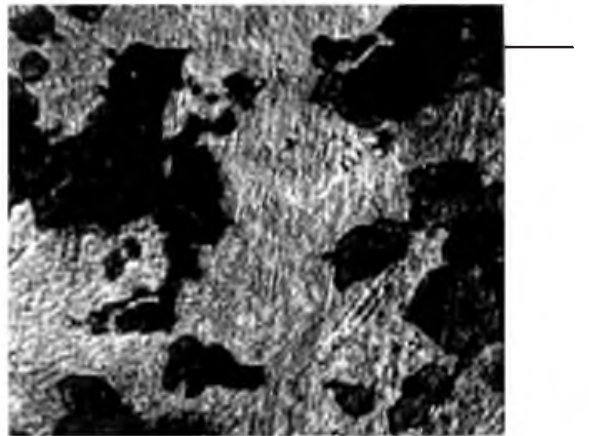

6

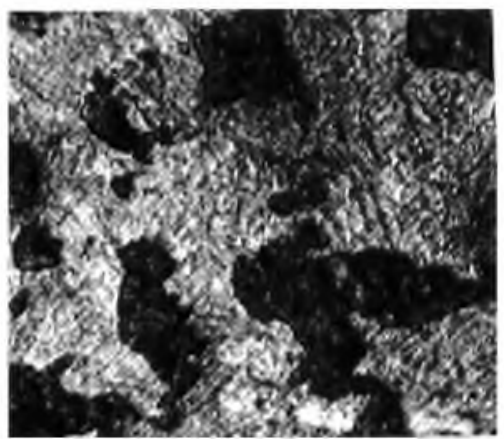

r

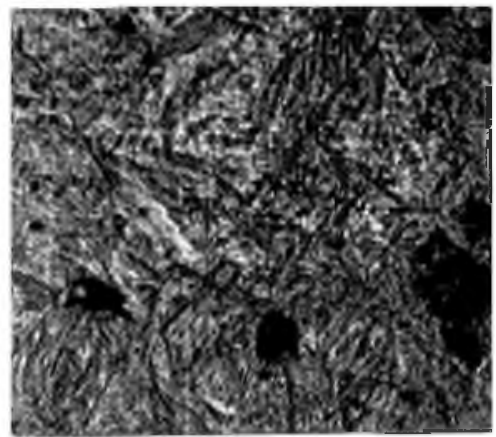

Рис. 7.

Микроструктуры стали У8 после закалки в магнитной жидкости $\left(\varphi_{m}=0,0159\right)$ в магнитных полях,

Т: $\mathbf{a}-0 ; 6-0,0220 ;$ в - 0,0370; г - 0,0525; д - 0,0680; e $-0,0980 ; ж-0,1250$

Fig. 7. The microstructures of steel U8 after quenching in a magnetic fluid $\left(\varphi_{m}=0.0159\right)$ in magnetic fields, $\mathrm{T}: \mathrm{a}-0 ; \mathrm{b}-0.0220$ B - 0.0370; $g-0.0525 ;$ д -0,0680; e = 0.0980; $f-0,1250$ 

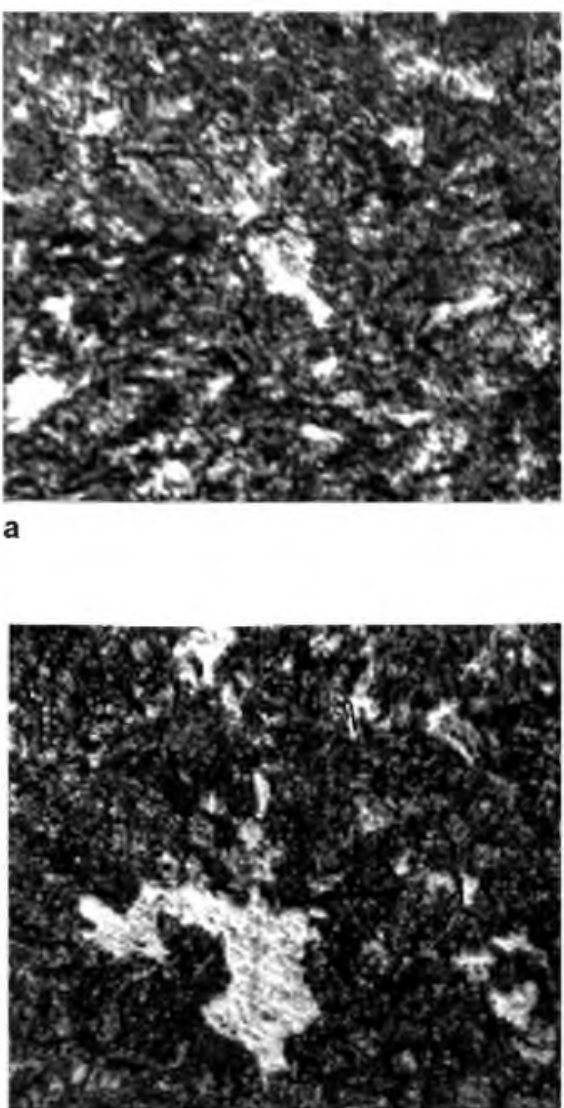

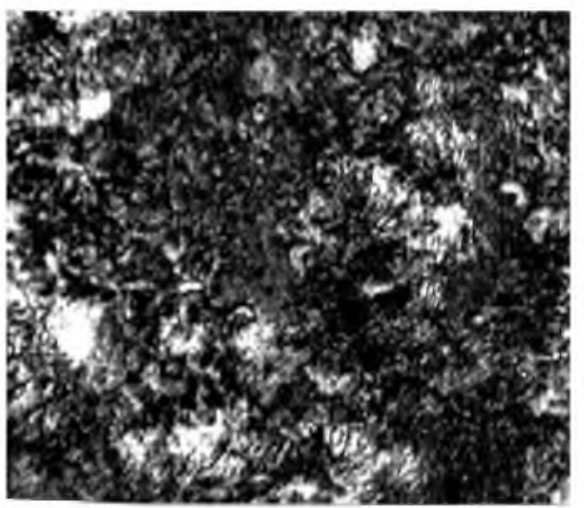

б

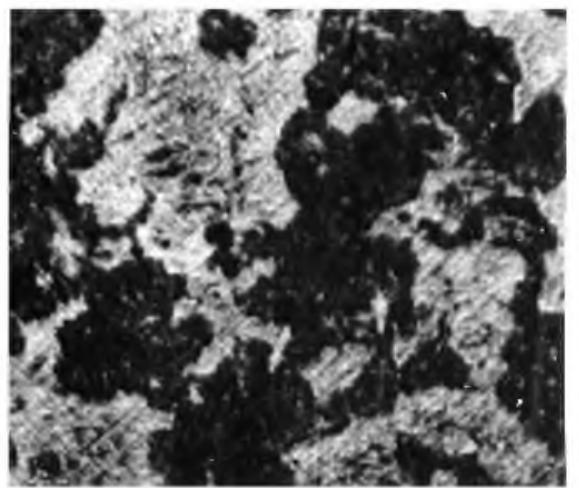

Pис. 8.

Микроструктуры стали У8 после закалки в магнитной жидкости $\left(\varphi_{m}=0,0023\right)$ в магнитных полях,

T: a $-0 ; \sigma-0,0980 ; B-0,1930 ; r-0,2130$

Fig. 8. The microstructures of $U 8$ steel after quenching in a magnetic liquid $\left(\varphi_{m}=0.0023\right)$ in magnetic fields, $\mathrm{T}: \mathrm{a}-0 ; \mathrm{b}-0.0980 ; \mathrm{B}-$ 0,$1930 ; g-0.2130$

Как и при закалке стали 50 с уменьшением объемной доли магнитной фазы в магнитной жидкости магнитным полем удается все более плавно управлять ходом фазовых превращений в стали при охлаждении.

На рис. 7 а-ж представлены фотографии микроструктур стали У8, полученных в результате закалки в растворе магнитной жидкости с объемной долей магнитной фазы 
$\varphi_{m}=0,0159$ в магнитных полях различной интенсивности. После закалки без магнитного поля (рис. 7а) структура образцов - троостомартенсит - на фотографии видно чередование темных трооститных и светлых мартенситных областей. В связи с малой величиной зерна игольчатый характер структуры мартенсита не просматривается. С увеличением магнитного поля до значений $0,0525 \mathrm{~T}$ троостиные включения в структуре все еще обнаруживаются. Указанный характер изменений отражен на рис. 7б - 7г, где приведены фотографии микроструктур стали У8, полученных в результате закалки в полях 0,$0220 ; 0,0370$ и 0,0525 Т соответственно. Как и ранее, хорошо протравленные темные области - троостит, светлый фон со слабо просматриваемой игольчатой структурой - мартенсит. При закалке в магнитном поле $0,0680 \mathrm{~T}$ троостит в структурах не обнаруживается (рис. 7 д). Однако, хорошо видны последствия процесса отпуска - укрупнены игловидные образования - характерная структура мартенсита отпуска. С дальнейшим увеличением магнитного поля вновь успевают происходить диффузионные процессы, и в структуре появляются области троостита (рис. 7 е, ж). При закалке стали У8 в наиболее слабоконщентрированном растворе магнитной жидкости в полях до 0,2 Т скорость охлаждения оказывается ниже критической для данной марки стали, что не позволяет получать структуры, свободные от продуктов распада аустенита.

На рис. 8а приведена фотография микроструктуры стали У8, полученной в результате закалки в растворе магнитной жидкости с объемной долей магнитной фазы $\varphi_{m}=0,0023$ в отсутствие магнитного поля. Видны светлые области - мартенсит, в различной степени протравленные области - сорбит и троостит. В отдельных местах заметны сформировавшиеся области перлита, на светлом фоне перлита параллельные пластины цементита.

Подобное многообразие фаз в структуре характерно и для образцов, закаленных в поле 0,0980 T - рис. 8б.

Последовательное уменьшение объема продуктов перлитного превращения - сорбита и троостита, как следует из фотографий микроструктур, приведенных на рис. 8 в и г, происходит в полях 0,1930 и $0,2130 \mathrm{~T}$.

В результате рентгеноструктурного анализа определены изменения в количественном содержании остаточного аустенита образцов стали У8, закаленных в растворах магнитной жидкости с различным содержанием магнитной фазы при наложении магнитных полей различной интенсивности.

На рис. 9 приведены графики зависимости интенсивности линий (002) аустенита от величины прикладываемого магнитного поля. Кривая 1 соответствует интенсивности линии (002) аустенита для образцов, закаленных в жидкости с $\varphi_{m}=0,0294$. Кривая 2 характеризует изменения уровня интенсивности линии (002) аустенита для образцов, закаленных в жидкости с $\varphi_{m}=0,0159$. Поведение кривой 3 соответствует изменениям интенсивности линий (002) аустенита образцов, закаленных в жидкости с $\varphi_{m}=0,0023$. Кривая 4 соответс- 
твует уровню интенсивности линии (002) аустенита в образцах, закаленных в воде, имеющей начальную температуру $24{ }^{\circ} \mathrm{C}$. Видно, что наложением магнитного поля удается управлять количеством остаточного аустенита в стали при закалке в конщентрированной жидкости от уровня, меньшего, чем при закалке в воде, до большего уровня. Некоторое количество остаточного аустенита обнаруживается и при закалке в слабоконщентрированном растворе магнит-

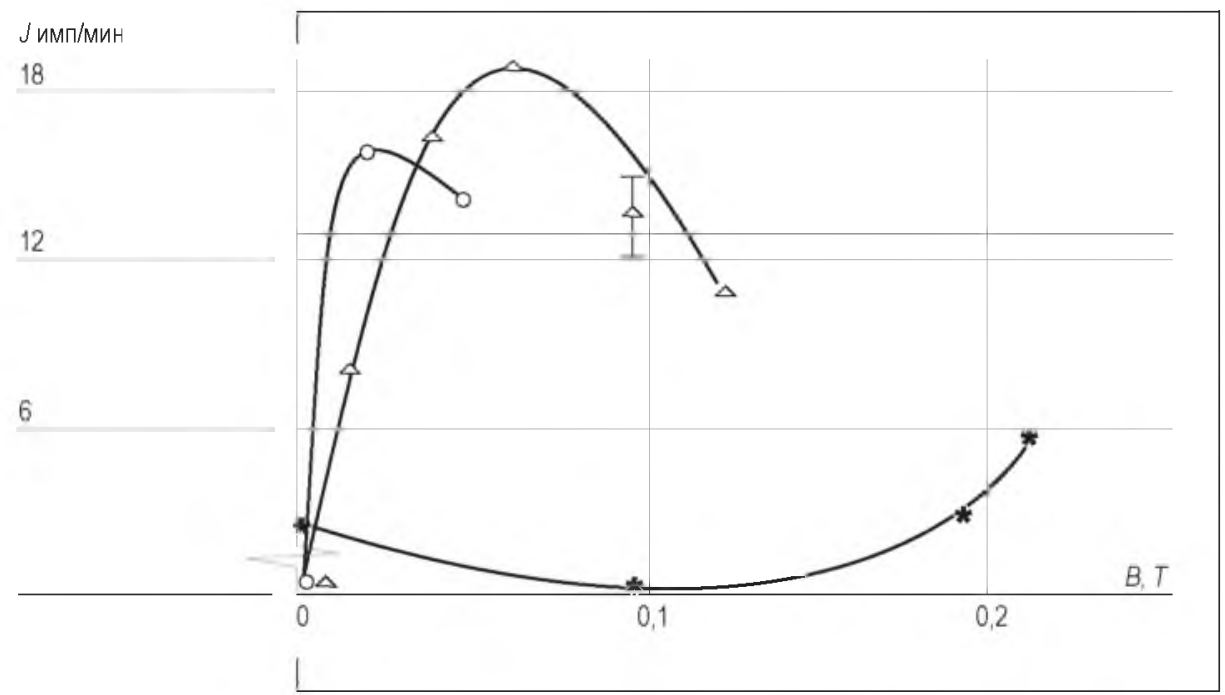

Рис. 9.

График зависимости интенсивности линии (002) аустенита на рентгенограммах от величины прикладываемого магнитного поля у образцов из стали У8, закаленных в магнитной жидкости с $\varphi_{m}$ :

$0-0,0294 ; \triangle-0,0159 ; *-0,0023$.

Прямая линия - уровень интенсивности линии (002) аустенита у образцов, закаленных в воде.

Fig. 9. A plot of the intensity of the austenite line (002) on X-ray diffraction patterns from the magnitude of the applied magnetic field in samples of steel U8 quenched in a magnetic fluid with $\varphi_{m}: 0-$ 0,$0294 ; \Delta-0,0159 ; *-0,0023$. The straight line is the intensity level of the austenite line (002) for samples quenched in water.

ной жидкости. Более высокий уровень остаточного аустенита в образцах, закаленных в магнитной жидкости, может быть обусловлен рядом причин.

С одной стороны, более интенсивным, нежели в воде, охлаждением в интервале температур мартенситного превращения. Другим возможным механизмом увеличения ко- 
личества остаточного аустенита в стали может явиться соответствующее перераспределение фазовых напряжений за счет неоднородного охлаждения, что затрудняет сдвиг атомных плоскостей в период мартенситного превращения.

\section{Выводы}

Впервые, основываясь на результатах изучения термогидродинамических явлений при охлаждении твердых тел в магнитной жидкости, предложена новая область технического использования магнитной жидкости - в качестве закалочной среды в процессах термической обработки. Возможность применения магнитной жидкости в качестве закалочной среды подтверждена экспериментами по закалке углеродистых и низколегированных сталей. Показано, что путем изменения интенсивности магнитного поля при закалке в магнитной жидкости сталей с пониженной устойчивостью переохлажденного аустенита можно добиваться как диффузионного, так и бездиффузионного механизмов превращения и, тем самым, управлять фазовым составом сталей. Найдено, что путем изменения интенсивности магнитного поля при закалке в магнитной жидкости образцов малых размеров из сталей с пониженной устойчивостью переохлажденного аустенита можно управлять их твердостью.

Результаты исследований позволили выявить новое перспективное направление при использовании магнитной жидкости в качестве закалочной среды - проведение закалочного охлаждения с заданной локальной неоднородностью. Возникновение в магнитной жидкости на поверхности закаливаемых изделий паровых полостей, положение которых обусловлено конфигурацией магнитного поля, дает основание для проведения охлаждения различных участков поверхности деталей с различной скоростью. Проведение неоднородного охлаждения поверхности по заранее заданной схеме позволит управлять распределением текущих и остаточных напряжений в изделиях, что даст основание для работы над одной из важнейших проблем машиностроения - осуществления бездеформационной закалки.

\section{Библиографический список}

1. А.С. 985076 СССР. Закалочная среда / Ставропольский пед. институт, авт.изобретение В.В.Чеканов, А.Я. Симоновский. Заявл. 26.05.81. № 3294878/22-02; опубл.30.12.82// Б.И., 1982 №48.

2. Симоновский А.Я. Теплоперенос при закалочном охлаждении в магнитной жидкости // Магнитная гидродинамика. 1988. №2 C. $67-72$.

3. Верховский С.Н., Миркин Л.И., Симоновский А.Я. Структура и свойства сталей после управляемой закалки в магнитной жидкости // Физика и химия обработки материалов. 1990. № 2 C. $127-132$. 
4. Гогосов В. В., Симоновский А. Я. О локально-неоднородном охлаждени при закалке в магнитной жидкости // Изв. АН СССР. Механика жидкости и газа. 1989. № 2. С. 3.

5. Gogosov V. V., Simonovskii A. Ya., Smolkin R. D. Quenching and separation in magnetic fluids // JMMM. 1990. V. 85. №. 1-3. P. 227.

6. Mirkin L.I., Shesterikov S.A., Simonovski A.Y. Equipment and method for quenching steels in a magnetic liquid // 1993. V.U.Z. Mashinostr. V. 6. P. 1.

7. Блантер М.Е. Теория термической обработки стали. М.: Металлургия, 1984. 328 с.

8. Металловедение и термическая обработка стали: Справочник. Т. III. Термическая обработка металлопродукции / под ред. М.Л. Бернштейна и А.Г Р.ахштадта. М.: Металлургия, 1983. - 216с

9. Журавлев В.Н., Николаева О.И. Машиностроительные стали: Справочник. М.: Машиностроение, 1981. 391 с.

10. Металловедение и термическая обработка стали: Справочник. М.: Машиностроение, 1983. 352 с.

11. Гуляев А.П. Металловедение. М.: Металлургия, 1977. 647с.

\section{References}

1. A. C. 985076 of the USSR. The hardening environment / Stavropol PED. Institute, ed.the invention V. V. Chekanov, Y. A. Simonov. Declared. 26.05.81. No. 3294878/22-02; publ.30.12.82 // B. I., 1982. No. 48.

2. Simonovsky A. Ya. heat Transfer during quenching cooling in magnetic fluid // Magnetic hydrodynamics. 1988. №2. P. 67-72.

3. Verkhovsky S. N., Mirkin L. I., Simonov A. Y. Structure and properties of steels after controlled quenching in a magnetic fluid // physics and chemistry of materials processing. 1990. No. 2. P. 127-132

4. Gogosov V. V., Simonovskij A. Ya. On locally inhomogeneous cooling when tempering in a magnetic fluid, IzV. USSR ACADEMY OF SCIENCES. Fluid and gas mechanics. 1989. No. 2. P. 3.

5. Gogosov V. V., Simonovskii A. Ya., Smolkin R. D. Quenching and separation in magnetic fluids // JMMM. 1990. V. 85. №. 1-3. P. 227.

6. Mirkin L.I., Shesterikov S.A., Simonovski A.Y. Equipment and method for quenching steels in a magnetic liquid // 1993. V.U.Z. Mashinostr. V. 6 P. 1.

7. Blanter M. E. Theory of heat treatment of steel. M.: Metallurgy, 1984. $328 \mathrm{c}$.

8. The metallography and heat treatment of steel: Reference book. Vol. III. Heat treatment of metal products / ed. M. L. Bernstein and A.G. Rachstadt. M.: Metallurgy, 1983. 216 c

9. Zhuravlev V. N., Nikolaev O. I. Machine-building steel: Reference M.: Mechanical Engineering, 1981. - 391c

10. The metallography and heat treatment of steel: Reference book. M. Mechanical Engineering, 1983. $352 \mathrm{c}$.

11. Gulyaev A. P. Physical Metallurgy. M.: Metallurgy, 1977.- 647c. 
Благодарности: выражаем благодарность РФФИ за поддержку работы (грант № 17-01-00037).

Acknowledgments: We express our gratitude to the RFBR for the support of the work (Grant No. 17-01-00037).

\section{Исследование проведено в рамках гранта РФФИ 17-01-00037.}

\section{O6 авторе: \\ Симоновский Александр Яковлевич,}

1. профессор кафедры общей и теоретической физики ИМЭН СКФУ $(355009$, г. Ставрополь, ул. Пушкина, 1$)$, доктор физикоматематических наук, профессор

2. профессор кафедры математики ФГБОУ ВО «Ставропольский государственный аграрный университет» (355017, Россия г. Ставрополь, пер. Зоотехнический 12), ORCID: https://orcid.org/0000-0002-9346-8950, Scopus ID: 7801335487, simonovchkij@mail.ru.

\footnotetext{
About the author:

Simonovsky Alexander Yakovlevich,

1. Professor of the Department of General and Theoretical Physics, IMEN SKFU (355009, Stavropol, Pushkin Street, 1), Doctor of Physics and Mathematics, Professor:

2. Professor of the Department of Mathematics of the St. Petersburg State Agrarian University "Stavropol State Agrarian University" (355017, Russia, Stavropol, Zootechnical 12), ORCID: https://orcid. org/0000-0002-9346-8950, Scopus ID: 7801335487, simonovchkij@mail.ru.
} 